University of Wollongong

Research Online

Faculty of Engineering and Information

Faculty of Engineering and Information

Sciences - Papers: Part A

Sciences

$1-1-2007$

\title{
Influence of dog-bone apex on shape during slab horizontal rolling process
}

Hai-liang Yu

Northeastern University, hailiang@uow.edu.au

Xiang-hua Liu

Northeastern University, liuxh@uow.edu.au

Chang-sheng Li

Northeastern University

Guo-dong Wang

Northeastern University

Follow this and additional works at: https://ro.uow.edu.au/eispapers

Part of the Engineering Commons, and the Science and Technology Studies Commons

Research Online is the open access institutional repository for the University of Wollongong. For further information contact the UOW Library: research-pubs@uow.edu.au 


\title{
Influence of dog-bone apex on shape during slab horizontal rolling process
}

\author{
Abstract \\ The deformation of slab with dog-bone shape during the horizontal rolling process was simulated using \\ FEM, and the influences of apical dislocation of dog-bone on the slab spread as well as the minimum crop \\ end loss and the lost width at slab head and tail were analyzed. The results show that with the increase in \\ the apical dislocation of dog-bone (LA), the slab spread and the minimum crop end loss at slab head and \\ tail decrease, while the lost width at slab head and tail increases. Meanwhile, the relationships of S/LA- \\ LA, LH/LA-LA, WH/LA-LA, LT/LA-LA, and WT/LA-LA were obtained. @ 2007 Central Iron and Steel \\ Research Institute. \\ Keywords \\ bone, influence, apex, dog, shape, during, slab, horizontal, rolling, process \\ Disciplines \\ Engineering | Science and Technology Studies \\ Publication Details \\ Yu, H., Liu, X., Li, C. \& Wang, G. (2007). Influence of dog-bone apex on shape during slab horizontal rolling \\ process. Journal of Iron and Steel Research International, 14 (3), 38-42.
}




\title{
Influence of Dog-Bone Apex on Shape During Slab Horizontal Rolling Process
}

\author{
YU Hai-liang, LIU Xiang-hua, LI Chang-sheng, WANG Guo-dong \\ (State Key Laboratory of Rolling and Automation, Northeastern University, Shenyang 110004, Liaoning, China)
}

\begin{abstract}
The deformation of slab with dog-bone shape during the horizontal rolling process was simulated using FEM, and the influences of apical dislocation of dog-bone on the slab spread as well as the minimum crop end loss and the lost width at slab head and tail were analyzed. The results show that with the increase in the apical dislocation of dog-bone $\left(L_{\mathrm{A}}\right)$, the slab spread and the minimum crop end loss at slab head and tail decrease, while the lost width at slab head and tail increases. Meanwhile, the relationships of $S / L_{\mathrm{A}}-L_{\mathrm{A}}, L_{\mathrm{H}} / L_{\mathrm{A}}-L_{\mathrm{A}}, W_{\mathrm{H}} / L_{\mathrm{A}}-L_{\mathrm{A}}, L_{\mathrm{T}} / L_{\mathrm{A}}-$ $L_{\mathrm{A}}$, and $W_{\mathrm{T}} / L_{\mathrm{A}}-L_{\mathrm{A}}$ were obtained.
\end{abstract}

Key words: dog-bone; apical dislocation; horizontal rolling; FEM

The dog-bone shape is deformed in slabs during the vertical rolling process and the sizing press process and so on; this slab deformation and the action during the rolling process have been widely researched. For example, the rigid-plastic formulation and some simplified assumptions were taken into account by Mori $\mathrm{K}$ et $\mathrm{al}^{[1]}$; and the incremental viscoplastic model by David $\mathrm{C}$ et al ${ }^{[2]}$ assumed a dog-bone shape as the function of friction; an non-steady state vertical-horizontal rolling process in roughing trains using the 3D finite element method (FEM) was studied by XIONG Shang-wu et $\mathrm{al}^{[3]}$; YU Hai-liang et $\mathrm{al}^{[4]}$ researched the slab corner metal flow condition during the multi-pass $\mathrm{V}-\mathrm{H}$ rolling process using FEM; LIU Hui et $a^{[5]}$ analyzed the effect of edger share on the slab profile with explicit dynamic FEM; and in the meantime, FENG Xian-zhang et $\mathrm{al}^{[6]} \mathrm{em}^{-}$ ployed the FEM to analyze the slab bulge distribution during sizing press (SP). The horizontal rolling for slabs with dog-bone shape was studied using $3 \mathrm{D}$ rigid-plastic FEM in Ref. [7], which proved that the FEM can be used to analyze the horizontal rolling process for slabs with dog-bone shape by comparing the calculated results and the experimental results.
During the V-H rolling process and the SP process, the apical dislocation of dog-bone will change for different vertical roll shapes ${ }^{[4,5]}$ and $\mathrm{SP}^{[6]}$ rolling condition. However, no report on the influence of apical dislocation of 'dog-bone' on slab deformation has been found.

In this study, the horizontal rolling processes for slab with dog-bone shape were simulated under different apical dislocation of dog-bone using explicit dynamic FEM and the influences of the apical dislocation of dog-bone in slab on the slab deformation at head and tail, and spread were analyzed.

\section{FEM Simulation}

\section{1 Basic parameters and rolling conditions}

The horizontal rolling process for slab with dogbone shape was simulated, and the diameter of the horizontal roll was $1150 \mathrm{~mm}$. The dimensions of the slab profile are shown in Fig. 1, in which the apical dislocation of dog-bone, $L_{\mathrm{A}}$, is equal to $120 \mathrm{~mm}$, $80 \mathrm{~mm}, 60 \mathrm{~mm}, 40 \mathrm{~mm}, 20 \mathrm{~mm}, 10 \mathrm{~mm}, 5 \mathrm{~mm}$, respectively.

The main chemical composition of the slab is (mass percent, \%): C $0.18, \mathrm{Si} 0.32$, and $\mathrm{Mn} 0.82$. The

\footnotetext{
Foundation Item: Item Sponsored by State Basic Research Key Projects (973) of China (2006CB605208-1) and National Natural Science Foundation of China (50534020)

Biography: YU Hai-liang(1980-), Male, Doctor Candidate; E-mail: yuhailiang1980@tom. com; Revised Date: March 30, 2006
} 


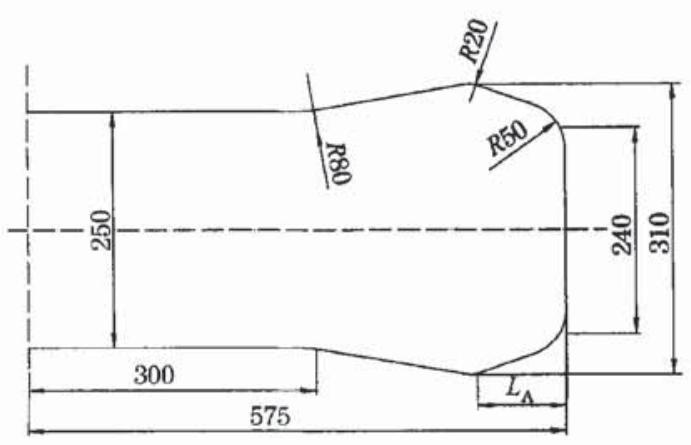

Fig. 1 Dimension of 'dog-bone' slab

yield stress at the high temperature is related to the true strain $\varepsilon$, the strain velocity $\dot{\varepsilon}$, and the deformation temperature $T$. During this simulation, the yield stresses were computed using Eqn. (1).

$$
\sigma=A \varepsilon^{B} \dot{\varepsilon}^{\cdot C T+D} \mathrm{e}^{F T}
$$

where $A, B, C, D$, and $F$ are constant.

During the rolling process, the rolling velocity is $4 \mathrm{~m} / \mathrm{s}$, and the slab draft is $10 \mathrm{~mm}$; the coefficient of friction is 0.35 .

\subsection{Building of models}

Owing to the symmetry of the slab with dogbone shape and the rolls, 1/4 of the slab and rolls were included in the geometric model. The rolling models were built according to the parameters mentioned above. The rolls were considered as rigid body since their deformation could be neglected. At the same time, these just refined the element near the slab margin where the deformation assembled. The entire geometric model was dispersed with 8 nodes and hexahedral elements. The nodes on the bottom face of the slab were constrained in the $Y$ direction, and the nodes on the center face of the slab were constrained in the $X$ direction. The geometrical model and meshing of the rolling process are shown in Fig. 2. During simulation, the slab enters the roll with an initial velocity and aparts from the roll under the friction force. The time of entire rolling process is $0.5 \mathrm{~s}$.

\section{Results and Discussion}

\section{1 Slab spread}

Table 1 shows the spread of slab at different $L_{\mathrm{A}}$ values. It can be seen that the spread of the slab decreases with the increase in $L_{\mathrm{A}}$. When $L_{\mathrm{A}}=120 \mathrm{~mm}$, the spread of the slab is $19.1 \mathrm{~mm}$, and when $L_{\mathrm{A}}=5 \mathrm{~mm}$, the spread of the slab is $25.9 \mathrm{~mm}$.

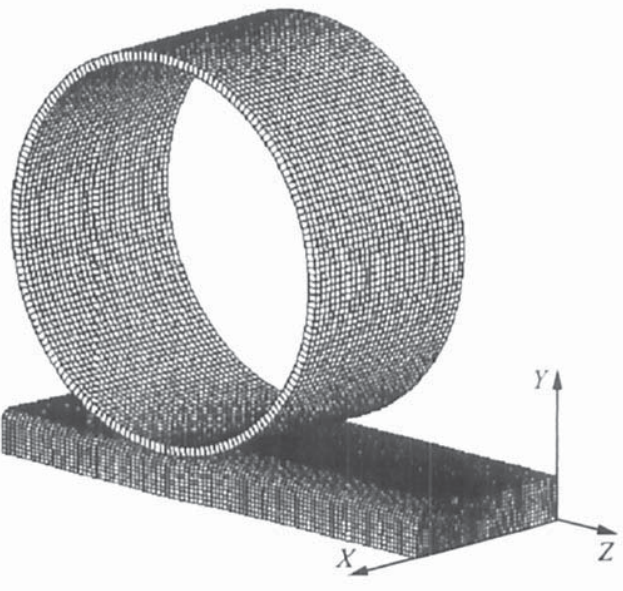

Fig. 2 FEM model for rolling process

Table 1 Slab spread

\begin{tabular}{cccccccc}
\hline$L_{\mathrm{A}} / \mathrm{mm}$ & 120 & 80 & 60 & 40 & 20 & 10 & 5 \\
\hline Spread $/ \mathrm{mm}$ & 19.1 & 21.2 & 22.4 & 23.7 & 24.6 & 25.2 & 25.9 \\
\hline
\end{tabular}

Fig. 3 shows the spread percentage of the slab at different $L_{\mathrm{A}}$ values. With the increase in $L_{\mathrm{A}}$, the spread percentage decreases, and under the rolling condition, the spread percentage of the slab varies from $3.3 \%$ to $4.5 \%$. By further analysis of the spread of the slab, let $S / L_{\mathrm{A}}$ [the ratio of spread of slab $(S)$ to corresponding $\left.L_{\mathrm{A}}\right]$ be $Y$ axis and $L_{\mathrm{A}}$ be $X$ axis, and the curve is drawn, as shown in Fig. 4. With the increase in $L_{\mathrm{A}}, S / L_{\mathrm{A}}$ decreases. Thus, the curve can be fitted by Eqn. (2).

$$
y=A_{1} \mathrm{e}^{\left(-x / \iota_{1}\right)}+A_{2} \mathrm{e}^{\left(-x / \iota_{2}\right)}+y_{0}
$$

where $A_{1}, t_{1}, A_{2}, t_{2}$, and $y_{0}$ are constants, and are set to be $11.74151,3.86243,2.20111,25.46362$, and 0.15354 , respectively, during the simulation.

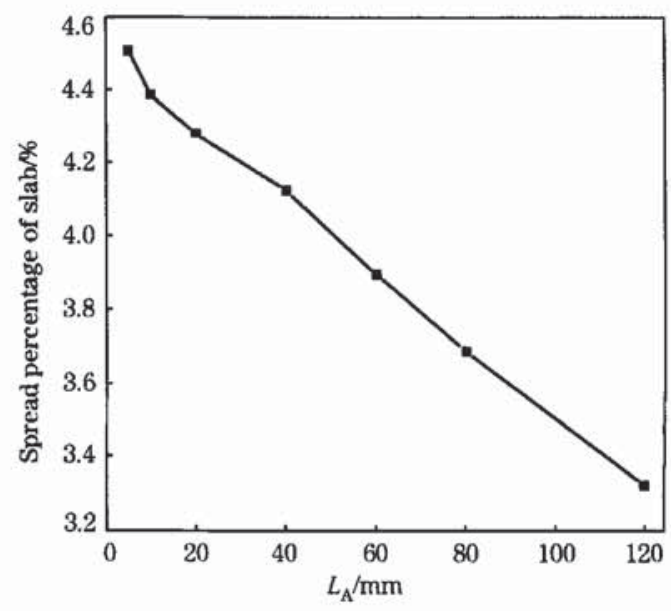

Fig. 3 Influence of apical dislocation of 'dog-bone' on spread percentage 


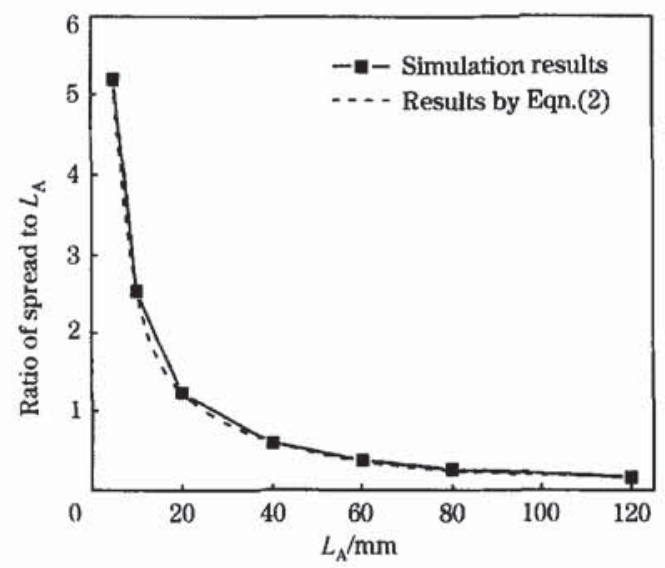

Fig. 4 Relationship between $S / L_{\mathrm{A}}$ and $L_{\mathrm{A}}$

\section{2 Deformation of slab head}

Fig. 5 (a) shows the shape of the slab head after rolling at different $L_{\mathrm{A}}$ values, in which $L_{\mathrm{H}}$ is the minimum crop end loss at the slab head, and $W_{\mathrm{H}}$ is the lost width at slab head. Fig. 5 (b) shows the changing rules of $L_{\mathrm{H}}$ and $W_{\mathrm{H}}$ at different $L_{\mathrm{A}}$ values. It can be seen that $W_{H}$ increases gradually with the increase in $L_{\mathrm{A}}$, and the amplification is large, from $30 \mathrm{~mm}$ to $130 \mathrm{~mm}$, whereas the $L_{\mathrm{H}}$ decreases gradually with the increase in $L_{A}$, from $45 \mathrm{~mm}$ to $36 \mathrm{~mm}$.

Further analysis of $L_{\mathrm{H}}$ and $W_{\mathrm{H}}$ was carried out. Let $L_{A}$ be the $X$ axis, and $L_{\mathrm{H}} / L_{\mathrm{A}}$ or $W_{\mathrm{H}} / L_{\mathrm{A}}$ be the $Y$ axis, the relationships of $W_{\mathrm{H}} / L_{\mathrm{A}}-L_{\mathrm{A}}$, and $L_{\mathrm{H}} / L_{\mathrm{A}}-$ $L_{\mathrm{A}}$ are shown in Fig. 6. It can be seen that the $L_{\mathrm{H}} /$ $L_{\mathrm{A}}$ and $W_{\mathrm{H}} / L_{\mathrm{A}}$ decrease with the increase in $L_{\mathrm{A}}$, and the relationships of $W_{\mathrm{H}} / L_{\mathrm{A}}-L_{\mathrm{A}}$ and $L_{\mathrm{H}} / L_{\mathrm{A}}-L_{\mathrm{A}}$ can be

fitted by Eqn. (3) and Eqn. (4), respectively.

$$
\begin{aligned}
& y=A_{13} \mathrm{e}^{\left(-x / t_{13}\right)}+A_{23} \mathrm{e}^{\left(-x / t_{23}\right)}+y_{03} \\
& y=A_{14} \mathrm{e}^{\left(-x / t_{14}\right)}+A_{24} \mathrm{e}^{\left(-x / t_{24}\right)}+y_{04}
\end{aligned}
$$

where $A_{1}, t_{1 i}, A_{2 i}, t_{2 i}, y_{0 i}$ are constants. During the simulation, the values of these constants are shown in Table 2 .
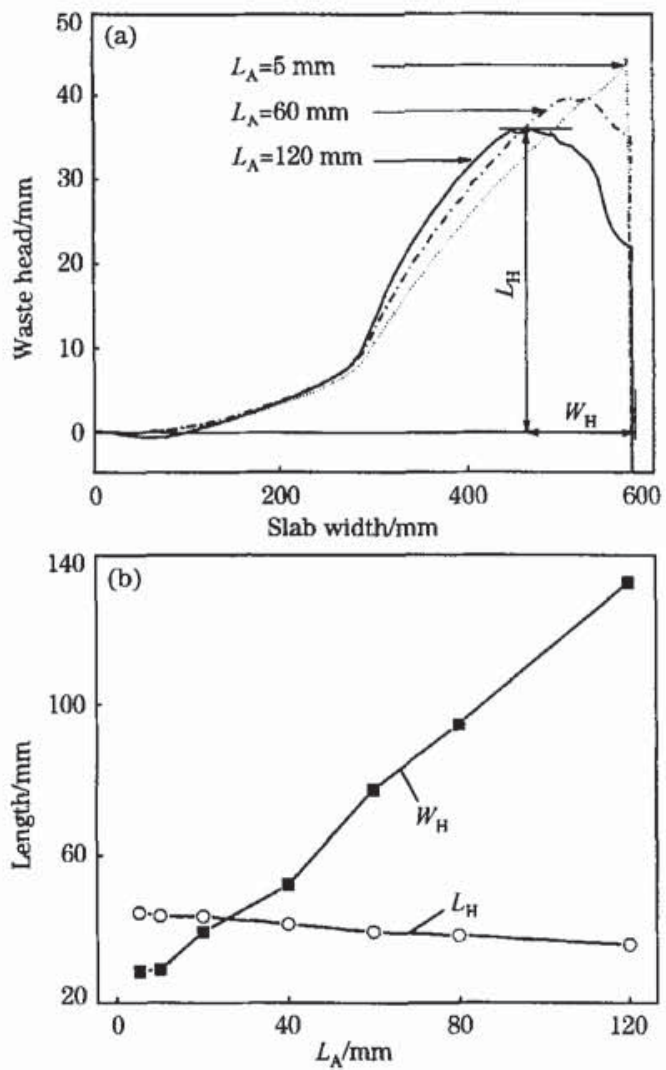

Fig. 5 Influence of $L_{A}$ on deformation of slab head
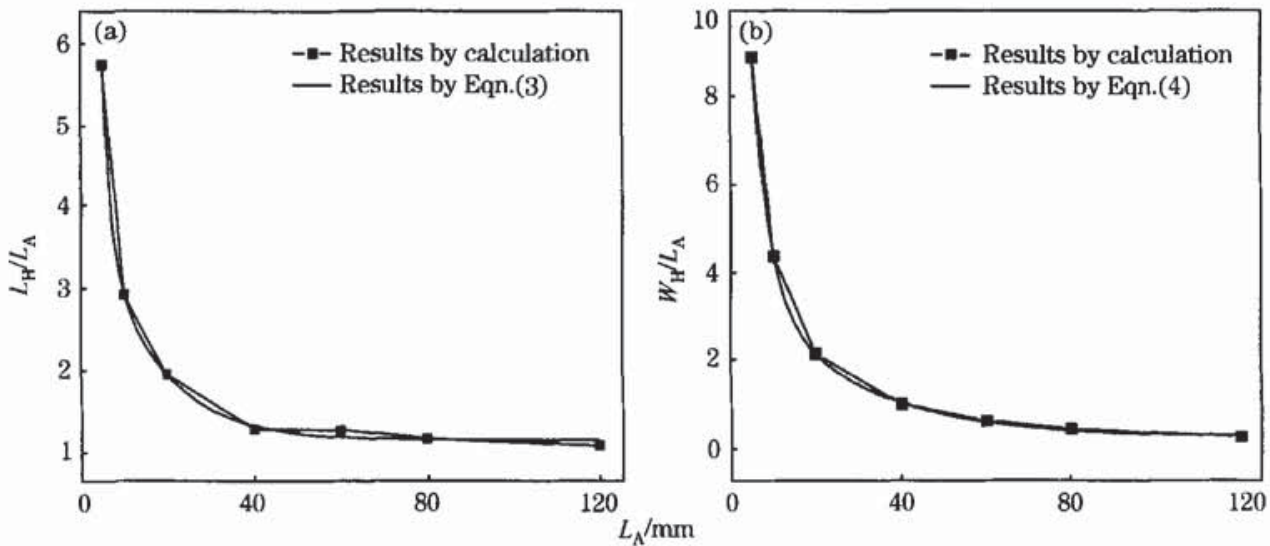

Fig. 6 Relationship of $L_{\mathrm{H}} / L_{\mathrm{A}}$ and $W_{\mathrm{H}} / L_{\mathrm{A}}$ to $L_{\mathrm{A}}$

Table 2 Value of constant

\begin{tabular}{cccccc}
\hline Constant & $A_{1 i}$ & $t_{1 i}$ & $A_{2 i}$ & $t_{2 i}$ & $y_{0 i}$ \\
\hline$i=3$ & 1.16265 & 46.12912 & 1.6413 & 3.44563 & 13.63016 \\
$i=4$ & 0.3008 & 4.05509 & 24.04506 & 20.27496 & 3.72932 \\
\hline
\end{tabular}




\subsection{Deformation of slab tail}

Fig. 7 (a) shows the shape of the slab tail after rolling at different $L_{\mathrm{A}}$ values, in which $L_{\mathrm{T}}$ is the minimum crop end loss at the slab tail, and $W_{\mathrm{T}}$ is the lost width at the slab tail. Fig. 7 (b) shows the changing rules of $L_{\mathrm{T}}$ and $W_{\mathrm{T}}$ at different $L_{\mathrm{A}}$ values. It can be seen that $W_{\mathrm{T}}$ increases gradually with the increase in $L_{\mathrm{A}}$, from $35 \mathrm{~mm}$ to $140 \mathrm{~mm}$, whereas the $L_{T}$ decreases gradually with the increase in $L_{A}$, from $45 \mathrm{~mm}$ to $41 \mathrm{~mm}$. By comparing Fig. 7 with Fig. 5 , it can be found that the deformation level of the tail is larger than that of the head.

Further analysis of $L_{\mathrm{T}}$ and $W_{\mathrm{T}}$ was carried out. Let $L_{\mathrm{A}}$ be the $X$ axis, and $L_{\mathrm{T}} / L_{\mathrm{A}}$ or $W_{\mathrm{T}} / L_{\mathrm{A}}$ be the $Y$ axis, the relationships of $L_{\mathrm{T}} / L_{\mathrm{A}}$ and $W_{\mathrm{T}} / L_{\mathrm{A}}$ to $L_{\mathrm{A}}$ are shown in Fig. 8. It can be seen that the $L_{\mathrm{T}} / L_{\mathrm{A}}$ and
$W_{\mathrm{T}} / L_{\mathrm{A}}$ values decrease with the increase in $L_{\mathrm{A}}$, and the relationships of $W_{\mathrm{T}} / L_{\mathrm{A}}$ and $L_{\mathrm{T}} / L_{\mathrm{A}}$ to $L_{\mathrm{A}}$ can be fitted by Eqn. (5) and Eqn. (6), respectively.

$$
\begin{aligned}
& y=A_{15} \mathrm{e}^{\left(-x / t_{15}\right)}+A_{25} \mathrm{e}^{\left(-x / t_{25}\right)}+y_{05} \\
& y=A_{16} \mathrm{e}^{\left(-x / t_{16}\right)}+A_{26} \mathrm{e}^{\left(-x / t_{26}\right)}+y_{06}
\end{aligned}
$$

where $A_{1 j}, t_{1 j}, A_{2 j}, t_{2 j}, y_{0 j}$ are constants. During the simulation, the values of these constants are shown in Table 3 .

\section{Conclusions}

(1) The slab spread decreases as the apical dislocation of dog-bone $L_{\mathrm{A}}$ increases.

(2) The minimum crop end loss of slab head and tail decreases, and the lost width of slab head and tail increases as the apical dislocation of dogbone $L_{\mathrm{A}}$ increases.

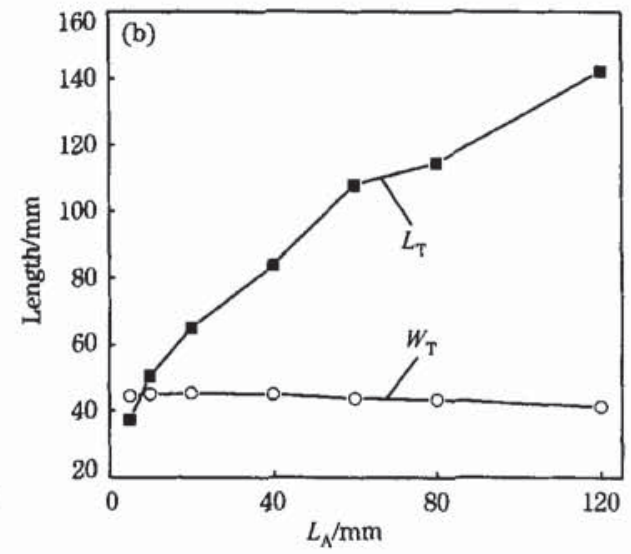

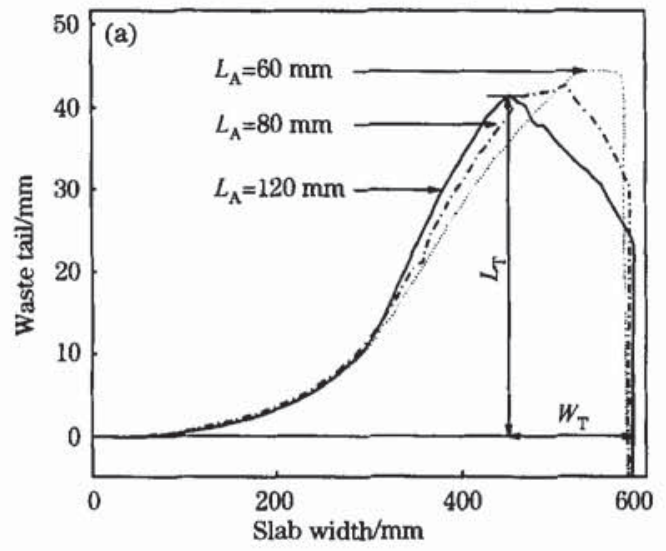

Fig. 7 Influence of $L_{\mathrm{A}}$ on deformation of slab tail
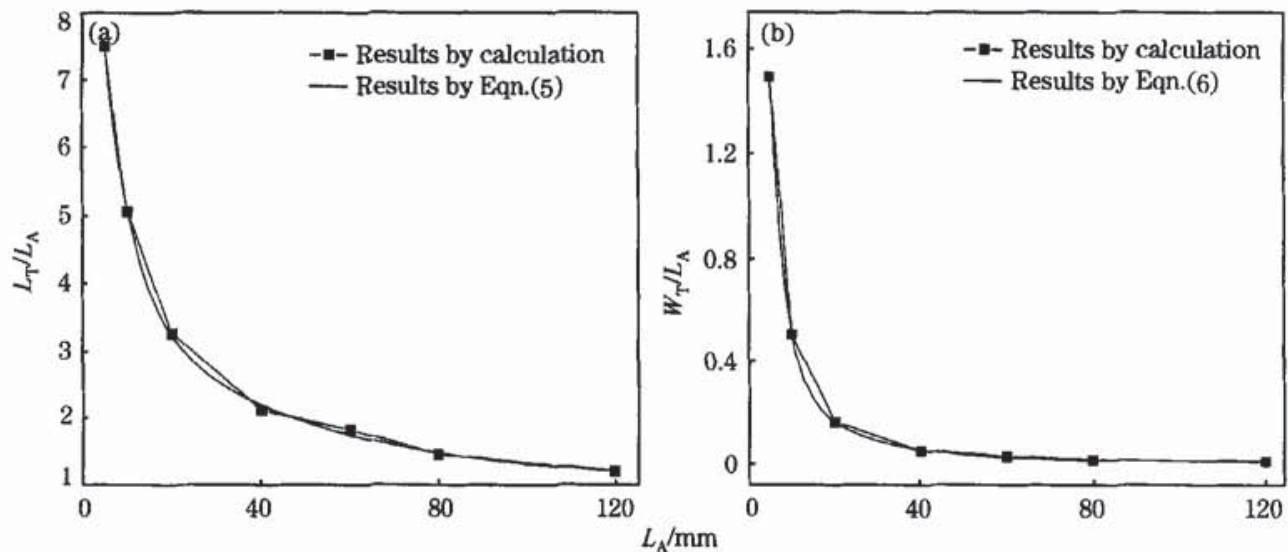

Fig. 8 Relationship of $L_{\tau} / L_{\mathrm{A}}$ and $W_{\mathrm{T}} / L_{\mathrm{A}}$ to $L_{\mathrm{A}}$

Table 3 Value of constant

\begin{tabular}{cccccc}
\hline Constant & $A_{1 j}$ & $t_{1 j}$ & $A_{2,}$ & $t_{2 j}$ & $y_{0}$, \\
\hline$j=5$ & 1.02029 & 2.94707 & 41.82648 & 8.47963 & 6.2752 \\
$j=6$ & 0.0125 & 6.44425 & 17.09011 & 5.40142 & 3.22994 \\
\hline
\end{tabular}


(3) Under certain conditions, the relationships of $S / L_{\mathrm{A}}-L_{\mathrm{A}}, L_{\mathrm{H}} / L_{\mathrm{A}}-L_{\mathrm{A}}, W_{\mathrm{H}} / L_{\mathrm{A}}-L_{\mathrm{A}}, L_{\mathrm{T}} / L_{\mathrm{A}}-L_{\mathrm{A}}$, and $W_{\mathrm{T}} / L_{\mathrm{A}}-L_{\mathrm{A}}$ are given.

\section{References:}

[1] Mori K, Osakada K. Simulation of Three-Dimensional Rolling by the Rigid-Plastic Finite Element Method [A]. Pittman J F $\mathrm{T}$, Wood R D, Alexander J M, et al, eds. Proceedings of the International Conference on Numerical Methods in Industrial Forming Processes [C]. Swabsea: Pineridge, 1982. 747-756.

[2] David C, Bertrand C, Chenot J L, et al. A Transient 3D FEM Analysis of Hot Rolling of Thick Slabs [A]. Proceedings of Numiform' 86 [C]. Rotterdam, Netherland: Balkema A A, 1986. 219-224.

[3] XIONG Shang-wu, LIU Xiang-hua, WANG Guo-dong, et al. Analysis of the Non-Steady State Vertical-Horizontal Rolling
Process in Roughing Trains by the Three-Dimensional Finite Element Method [J]. Journal of Materials Processing Technology, $2002,120(1-3)$ : 53-61.

[4] YU Hai-liang, LIU Xiang-hua, LI Chang-sheng. FEM Analysis to the Slab Corner Metal Flow Condition During Multi-Pass $\mathrm{V}-\mathrm{H}$ Rolling Process [J]. Journal of Northeastern University (Natural Science), 2005, 26(10): 982-985 (in Chinese).

[5] LIU Hui, GAO Cai-ru, WANG Guo-dong, et al. Effection of Edger Share on the Slab Profile [J]. Journal of Plasticity Engineering, 2003, 10(5): 86-88 (in Chinese).

[6] FENG Xian-zhang, LIU Cai. Finite Element Analysis of Slab Bulge Distribution During Sizing Press [J]. Metallurgical Equipment, 2004, 12(4): 1-3, 72 (in Chinese).

[7] XIONG Shang-wu, LU Cheng, LIU Xiang-hua, et al. Analysis of Horizontal Rolling for Slabs With Dog-Bone Shape by 3D Rigid-Plastic FEM [J]. Journal of Iron and Steel Research, 2000, 12(1): 14-17 (in Chinese).

\section{(Continued From Page 5)}

[2] YUAN Zhang-fu, GU Ke-jing. Characteristics of Swirl-Flow Oxygen Lance and Analysis of Its Application in Slag Splashing Technology [J]. Iron and Steel, 1998, 33(12): 17-20, 24 (in Chinese).

[3] Sakai A, Tani J, Yamada K, et al. Development of Low-Spitting Lance at Kashima's No. 2 Steelmaking Plant $[\mathrm{A}]$. 77th Steelmaking Conference $[\mathrm{C}]$. Warrendale, PA, USA; ISS, 1994. 61-66.

[4] Choi H S, Ryu J Y, Kim M R, et al. Modification of Lance Nozzle to Increase Productivity and BOF Lining Life at No. 2 Steelmaking Plant in Pohang Works [A]. 77th Steelmaking Conference [C]. Warrendale, PA, USA: ISS, 1994.
93-94.

[5] Higuchi Y, Tago Y. Effect of Nozzle Twisted Lance on Jet Behavior and Spitting Rate in Top Blown Process [J]. ISIJ Int, 2003, 43(9): 1410-1414.

[6] Swift T. BOF Oxygen Lance Improvements at Sparrows Point [A]. 84th Steelmaking Conference [C]. Warrendale, PA, USA: ISS, 2001. 525-540.

[7] Keilman L M, Galloway S M, Balajee S R, et al. Oxygen Lance Design Modifications to Improve the Lance Life and Performance at Inlands No. 2 BOF/CC Shop [A]. 76th Steelmaking Conference [C]. Warrendale, PA, USA: ISS, 1993. 145161. 